\title{
A DEMOCRACIA E O SERVIÇO SOCIAL
}

DEMOCRACY AND SOCIAL SERVICE

\section{MARTINS, Dialeny C. S. ; RODRIGUES, Karoline M.; TEIXEIRA, Juliana R.; CORDEIRO, Maria L. N.; FERREIRA, Solange $O$.}

\author{
Faculdade Leão Sampaio, Juazeiro do Norte (CE), Brasil
}

Recebido em: 12/05/2014; aceito: 04/11/2014; publicado em 19/11/2014

\section{RESUMO}

Este artigo é o resultado do trabalho em equipe das discentes na produção do conhecimento no âmbito acadêmico-profissional, com o objetivo de discutir sobre a democracia e sua relação com o Serviço Social. Diante disso, no presente estudo foi abordado um dos princípios fundamentais expresso no código de ética profissional de 1993, que se baseia na defesa do aprofundamento da democracia, enquanto socialização da participação política e da riqueza socialmente produzida. Os dados para este trabalho foram coletados a partir dos levantamentos bibliográficos em livros e artigos científicos, textos discutidos na disciplina de Ética profissional. A sociedade sua relação com a economia e sua influencia sobre o Serviço Social e a formação e atuação dos Assistentes Sociais. A importância deste, pois refletiu sobre um aspecto importante para a formação do assistente social e sua relação com a democracia.

Palavras-chave: Serviço Social; Código de Ética; Democracia.

\begin{abstract}
This article is the result of the teamwork of students in the production of knowledge in the academic-professional, with the goal of discussing about democracy and its relationship with Social services. Given this, we will discuss one of the fundamental principles expressed in the code of professional ethics of 1993, which is based on the defence of the deepening of democracy, while socialization of political participation and of socially produced wealth. The data for this study were collected from bibliographic surveys in books and scientific articles texts discussed in the discipline of professional ethics. Your relationship with society economy and its influence on Social services and the training and performance of social workers. The importance of this, as reflected on an important aspect for the formation of the social worker and his relationship with democracy.
\end{abstract}

Keywords: Social service. Code of Ethics. Democracy.

Keywords: Social service; Code of Ethics; Democracy. 


\section{INTRODUÇÃ̃O}

Este artigo é o resultado do trabalho em equipe das discentes na investigação e na produção do conhecimento no âmbito acadêmico-profissional, com o objetivo de discutir sobre a democracia e sua relação com o Serviço Social.

A sociedade busca no Serviço Social a resposta às demandas sociais. Diante disso, relata-se um dos princípios fundamentais expresso no código de ética profissional de 1993, que se baseia na defesa do aprofundamento da democracia, enquanto socialização da participação política e da riqueza socialmente produzida.

O projeto profissional na denominação "éticopolítico" se expressa eminentemente contemporânea, uma vez que sustenta a ressignificação da profissão numa perspectiva de renovação do ethos profissional e direção social crítica, assumindo um caráter substantivo de hegemonia, foi legitimada na Lei de Regulamentação da Profissão, no Código de ética aprovado em 1993 e nas Diretrizes Curriculares vigentes que, comumente fundamentam a resignação frente à produção e reprodução das apologias da ordem social contemporânea ${ }^{1}$.

A valorização da democracia consiste no reconhecimento nem sempre claramente explicitado, mas real, de que a democracia política moderna constitui uma conquista social que transcende os horizontes de classe para inscrever-se como um dado no processo global de criação do mundo social pelo homem tomado genericamente ${ }^{2}$.

Os dados para este trabalho foram coletados a partir de levantamentos bibliográficos em livros e artigos científicos sobre a democracia, a sua importância para a sociedade, sua relação com a economia e sua influencia sobre o Serviço Social e a formação e atuação dos Assistentes Sociais. O levantamento bibliográfico permitiu a construção do conhecimento sobre democracia e suas relações com o Serviço Social. Neste sentido foi possível dividir o trabalho em três seções, na primeira são realizadas considerações sobre a origem e quais as circunstâncias da democracia ao longo da evolução da sociedade; na segunda seção, é refletida a relação entre democracia e o contexto social, enfatizando o projeto ético-político do Serviço Social do código de ética; na terceira e última seção são delineadas observações sobre a importância do Serviço Social para a democracia.

A negociação da burguesia ocorre dentro dos limites imposto pelas instituições e pelos processos democráticos. Em geral são limites amplos, a participação e o controle popular nem sempre são vigorosos, a burguesia e a política e burocrática possuem enorme discernimento ${ }^{3}$.

A democracia é reduzida a um regime político eficaz, baseado na ideia de cidadania de organizada em partidos políticos, e se manifesta no processo eleitoral de escolha dos representantes, na rotatividade dos governantes e nas soluções técnicas para os problemas econômicos e sociais ${ }^{4}$.

O pensamento liberal que serve de fundamento para a democracia dos modernos subordina a condição de cidadão à propriedade privada. $\mathrm{O}$ status de cidadão, segundo as formulações do liberalismo clássico, conquista-se na sua relação com a propriedade. O estatuto de cidadão está subordinado à propriedade - é cidadão quem é proprietário. Essa visão tem como desdobramento uma perspectiva restrita de democracia, ou seja, a democracia que está na base do pensamento liberal é, na verdade, a democracia dos proprietários $^{5}$.

\section{REFERENCIAL TEÓRICO}

\subsection{DEMOCRACIA ENQUANTO VALOR UNIVERSAL FRENTE À DEMOCRACIA BURGUESA}

Um impulso para a participação democrática desenvolve-se a partir do que poderíamos chamar de lógica de igualdade. Por volta de 500 a.C. parece terem ressurgido condições favoráveis em diversos lugares, e alguns pequenos grupos de pessoas começaram a desenvolver sistemas de governo que proporcionavam oportunidades bastante amplas para participar em decisões de grupo ${ }^{3}$.

Democracia era um sistema que incluía algumas pessoas com plenos direitos, os quais eram negados a outras. Aqueles que usufruíam plenos direitos eram: Adultos, não crianças ou adolescentes; Homens, não mulheres; Os livres, não os escravos; Cidadãos, não estrangeiros. A democracia, portanto, era um sistema de autogoverno de um território por algumas pessoas que detinham plenos direitos ${ }^{6}$. 
Dessa forma, a democracia primitiva foi reinventada em uma forma mais avançada e os mais decisivos avanços ocorreram na Europa (três na costa do Mediterrâneo, outros na Europa do Norte). Os sistemas de governo que permitiam a participação popular de um significativo número de cidadãos foram estabelecidos pela primeira vez na Grécia clássica e em Roma (500 a.C.) em bases tão sólidas que resistiram por séculos, com algumas mudanças ocasionais ${ }^{3}$.

A Grécia era composta por centenas de cidades independentes, rodeadas de áreas rurais, a mais famosa foi Atenas, a qual em 507 a.C. os atenienses adotaram um sistema de governo popular que durou aproximadamente dois séculos, provavelmente foram eles que cunharam o termo demokratia: demos, o povo, e kratos, governar. Atenas foi um exemplo de participação dos cidadãos, era uma democracia participante ${ }^{3}$.

Os romanos chamaram seu sistema de república: res, que em latim significa coisa ou negócios, e publicus, ou seja, a república poderia ser interpretada como "a coisa pública" ou "os negócios do povo". Igual a Atenas, o direito de participar restringia-se a homens, o que também aconteceu em todas as democracias que apareceram depois, até o século $\mathrm{XX}^{3}$.

A liberdade era, segundo Aristóteles, "o princípio da prática democrática". A democracia dos antigos era restrita, tanto no sentido de que excluía grande parte de população da vida política, quanto no sentido de que aqueles que teoricamente deveriam ter acesso a ela, na prática, não usufruíam igualmente nem dos diretos políticos, nem dos bens materiais produzidos naquele momento ${ }^{5}$.

O sufrágio universal na Europa do século XIX, por exemplo, era um privilégio dos detentores de propriedade ou daqueles que pagavam uma certa quantia de impostos, ficando, dessa forma, excluída a maior parte da população do direito de votar. $\mathrm{O}$ voto universal masculino foi um direito conquistado apenas no final do século XIX e início do século $\mathrm{XX}$, sendo o voto feminino uma vitória bem mais recente $e^{5}$.

Mais do que qualquer outro aspecto, o sufrágio universal distingue a moderna democracia representativa de todas as formas anteriores de democracia. Durante 25 séculos, em todas as democracias e repúblicas, os direitos de se envolver plenamente na vida política estavam restritos a uma minoria de adultos e apenas no século XX é que tanto na teoria como na prática a democracia veio a exigir que os direitos de envolver-se plenamente na vida política deveriam ser estendidos, com pouquíssimas exceções a toda a população adulta com resistência permanente em um país ${ }^{3}$.

A democracia é, assim, reduzida a um regime político eficaz, baseado na ideia de cidadania organizada em partidos políticos, e se manifesta no processo eleitoral de escolha dos representantes, na rotatividade dos governantes e nas soluções técnicas para os problemas econômicos e sociais ${ }^{4}$.

A distinção entre democracia em sentido substantivo e democracia em sentido institucional é porventura a mais geral de todas as necessárias distinções. Democracia substantiva é o governo exercido a favor do povo ou especialmente vantajoso para o povo, entendido por povo o conjunto dos setores desfavorecidos entre titulares do direito de cidadania. A democracia aparece assim confundida com a ideia de justiça social: uma sociedade seria tanto mais democrática quanto maior fosse o nivelamento ou equalização das condições sociais. Democracia institucional é, na ordem interna de cada Estado, o poder político baseado na soberania popular ou nacional; é um sistema de organização do poder do Estado. Em sentido institucional, são democracias a democracia direta, a democracia convencional, a democracia representativa ou constitucional, a democracia plebiscitária e a democracia orgânica ${ }^{7}$.

A democracia institucional nasceu sob a forma de democracia direta, funcionou, e funcionaria, apenas em unidades políticas de pequena dimensão territorial. Regida pelo princípio da soberania popular, sendo os cidadãos uma pequena minoria da população da cidade; Democracia convencional é o sistema político caracterizado pelo poder ilimitado de um corpo representativo eleito, também designado por "governo de assembléia"7.

Democracia representativa ou constitucional é a organização do poder político, e da sua relação com os direitos das pessoas, caracterizada (a) pela exposição das decisões públicas ao generalizado e contraditório escrutínio dos cidadãos e (b) pelo princípio da representação, sendo (c) o poder judicial não só independente dos outros poderes, 
mas também imparcial e (d) o poder político exercido segundo a regra da maioria expressa pelo voto secreto eleitoral em regime de sufrágio universal com supremacia de câmara parlamentar (diretamente eleita) no processo de decisão legislativa, (e) no pressuposto da consagração e eficácia do igual direito de todos às liberdades e direitos fundamentais garantidos e observada divisão (ou mesmo separação) entre os poderes executivos e legislativo ${ }^{7}$.

Democracia plebiscitaria é, nos séculos XIX e XX, o sistema político em que o ditador (cesarista ou não) é eleito ou confirmado por sufrágio universal. Um plebiscito pode incidir ou sobre uma candidatura única, ou sobre pluralidade de candidaturas uma das quais oficial ou sobre pluralidade de candidaturas em condições institucionais igualitárias, é o regime que dispõe de maior expressão quantitativa no mundo contemporâneo ${ }^{7}$.

Democracia orgânica pode dizer-se do conjunto de sistemas políticos novecentistas em que a representação parlamentar foi substituída (ou o seu poder suplantado) por uma assembleia cujos membros são designados não pelo voto político individual dos cidadãos, mas por deliberação de coletividades representativas de interesses econômicos, profissionais, culturais ou morais. O que há de comum às várias democracias institucionais é o exercício do poder em nome do povo ou por mandato do povo ${ }^{7}$.

A universalidade da democracia não deve ser concebida apenas num sentido teórico, o valor da democracia não se limita a áreas geográficas ${ }^{8}$. Embora a democracia moderna entendida como exercício da liberdade em condições de máxima igualdade possível venha se tornando um valor universal, as formas de seu exercício são particulares a cada tempo e circunstância. O modelo de democracia norte americano não é exportável, ainda que fosse desejável; hoje em dia a democracia francesa, a democracia alemã, a democracia espanhola, a australiana ou mesmo a canadense dela são muito diferentes, Isso não significa que estejamos condenados a governos autocráticos por sermos diferentes, mas sim que inteiramente peculiar, e que a democracia ao sul da América, para ser sólida, tem de partir de nossos próprios territórios, clima, tradições, costumes, instituições políticas ${ }^{9}$.

Se por democracia moderna entende-se a democracia representativa, e se à democracia representativa é inerente a desvinculação do representante e aos seus interesses particularistas, então a democracia moderna pressupõe a atomização da nação e a sua recomposição num nível mais elevado e ao mesmo tempo mais restrito que é o das assembleias parlamentares. Mas tal processo de atomização é o mesmo processo do qual nasceu a concepção do Estado liberal, cujo fundamento deve ser buscado, na afirmação dos direitos naturais e invioláveis do indivíduo ${ }^{10}$. A crítica de Rousseau à democracia representativa pressupõe que o simples ato de votar em eleições não traduz a expressão da vontade popular ${ }^{5}$.

O quarto princípio do código de Ética do Assistente Social se da na defesa do aprofundamento da democracia enquanto socialização da participação política e da riqueza socialmente produzida ${ }^{11}$.

No Brasil, a Constituição Federal de 1988, assegura no art. $1^{\mathrm{o}}$ o Estado Democrático de direito, fundamentado na Soberania, cidadania, dignidade da pessoa humana, nos valores sociais do trabalho e da livre iniciativa e no pluralismo político. No parágrafo único é ressaltado que todo poder emana do povo, que o exerce por meio de representantes eleitos ou diretamente, nos termos desta Constituição $^{12}$.

O liberalismo é compatível com a democracia e esta pode ser considerada como o natural desenvolvimento do Estado liberal, pelo seu ideal igualitário e por sua fórmula política (soberania popular). Se os direitos de liberdade foram desde o início a condição necessária para a direta aplicação das regras do jogo democrático, é verdade que o desenvolvimento da democracia se tornou o principal instrumento para a defesa dos direitos de liberdade $^{10}$.

\subsection{A DEMOCRACIA E O CONTEXTO SOCIAL}

Para Rousseau, a voz do povo se faz ouvir por intermédio da vontade geral, que se consubstancia nas leis. Tudo gira, então, em torno da possibilidade de sabermos o que é a vontade geral. Para Rousseau à ideia de vontade geral, é a sua associação com as noções de bem comum e de interesse geral. Portanto, a relação entre vontade geral e interesse comum é uma relação intrínseca, de tal modo que é impossível pensar a primeira sem considerar a segunda ${ }^{13}$.

As teorias da modernização, afloradas após a II Guerra Mundial, entendiam que a modernização levaria, 
inevitavelmente, à institucionalização da democracia, ou seja, sinalizavam para o crescimento econômico, para a urbanização, para os índices crescentes de melhoria no nível educacional das populações e para a qualidade da saúde, somados a uma visão de futuro com confiança, que incidiriam em um processo virtuoso de construção democrática, pois tais sociedades demandariam cidadãos autônomos e organizados. Neste sentido, a modernização aparecia como pré-condição necessária para a emergência e a estabilidade de um governo democrático ${ }^{14}$.

Adam Smith transformou a economia em centro explicativo da sociedade através da universalidade do desejo de ganho dos homens. Sua solução afirma que os interesses privados, ao invés de se chocarem, produzindo a guerra, são agraciados por uma mão invisível que os orienta para o bemestar coletivo $^{15}$. Nessa ótica, o capitalismo de mercado é favorável à democracia por suas consequências sociais e políticas, criando um grande estrato intermediário de proprietários que normalmente buscam a educação, a autonomia, a liberdade pessoal, direitos de propriedade, a regra da lei e a participação no governo. Porém, parece não haver nenhuma correlação entre desenvolvimento econômico e o tipo de governo ou regime de um país, pois o desenvolvimento econômico não é exclusivo de países democráticos, nem a estagnação econômica é exclusiva das nações não-democráticas ${ }^{3}$.

Por outro lado, Marx acreditava que a democracia só é possível num sistema econômico socialista, sendo uma importante propaganda anticapitalista, onde o proletariado deve ser o grupo politicamente e economicamente dominante. $\mathrm{O}$ vínculo entre socialismo e democracia marcou sempre, desde o início, o processo de formação do pensamento marxista; e, direta ou indiretamente, esteve na raiz das inúmeras controvérsias que assinalaram e assinalam a história da evolução desse pensamento ${ }^{8}$.

Em relação ao Serviço Social, a participação e democracia têm sido enfatizados na formação e na atuação da profissão. Anterior ao contexto da democratização da sociedade brasileira dos anos 1980 a profissão abordava a participação numa perspectiva conservadora, da adesão a programas sociais, é nesta mesma década que a profissão passa a vincular a participação e a democracia à transformação social, com a construção de um projeto de sociedade mais justo e igualitário. Assim, os processos de descentralização político-administrativa do Estado brasileiro e a organização dos conselhos de direitos de políticas públicas, tem colocado ao profissional do Serviço Social, exigências de compreensão dos processos decisórios participativos e democráticos e de ação junto aos mesmos. Estas categorias são centrais no projeto ético-político da profissão, consolidadas nos princípios e nas condutas normativas orientadoras do agir profissional expressas no código de ética do assistente social ${ }^{16}$.

O conjunto das liberdades democráticas em sua forma moderna, o princípio da soberania e da representação popular, o reconhecimento legal do pluralismo, tem sua gênese histórica nas revoluções burguesas, ou mais precisamente, nos amplos movimentos populares que terminaram mais ou menos involuntariamente por abrir o espaço político necessário à consolidação e reprodução da economia capitalista ${ }^{8}$. Por isso, Marx não era contra a democracia, era a favor da emancipação humana, da plena liberdade dos homens, coisas que a democracia não pode proporcionar $^{17}$.

O partido político está diretamente ligado ao surgimento de uma classe operária numerosa, gerada pela Revolução Industrial, e à necessidade de incorporá-la ao sistema, de modo a conter o conflito político de classes antagônicas. Para os partidos socialistas, a defesa da participação das massas é condição de realização do governo democrático. Já no século XX, inscrevendo-se no campo teórico do marxismo, a tarefa a que se propõe inclui a atuação democrática na mobilização e educação das massas, para a realização da democracia como meio, que se afirma na participação em todas as etapas da construção do socialismo $^{18}$.

O projeto ético-político do Serviço Social tem em seu núcleo o reconhecimento da liberdade concebida historicamente como possibilidade de escolher entre alternativas concretas, portanto tem um compromisso com a autonomia, a emancipação e a plena expansão dos indivíduos sociais. Consequentemente, o projeto profissional vincula-se a um projeto societário que propõe a construção de uma nova ordem social, sem dominação e/ou exploração de classe, etnia e gênero. O projeto é democrático ressaltando a democratização enquanto socialização da 
participação política e socialização da riqueza socialmente produzida $^{19}$.

Do ponto de vista estritamente profissional, o projeto implica o compromisso com a competência, incluindo como base o aprimoramento intelectual do assistente social. Daí a ênfase numa formação acadêmica qualificada. Constata-se que este projeto ético-político, fundamentado teórica e metodologicamente, conquistou hegemonia no Serviço Social brasileiro na entrada dos anos 90. A ruptura do quase monopólio do conservadorismo no Serviço Social não suprimiu tendências conservadoras ou neoconservadoras ${ }^{19}$.

A conclusão deste projeto profissional acompanha a curva ascendente do movimento democrático e popular que progressista e positivamente, tensionou a sociedade brasileira entre a derrota da ditadura e a promulgação da constituição de $1988^{19}$.

$\mathrm{O}$ antagonismo entre o projeto ético-político que ganhou hegemonia no Serviço Social e a ofensiva neoliberal que, no Brasil, em nome da racionalização da modernidade, dos valores do primeiro mundo, vem promovendo a liquidação dos direitos sociais, a privatização do Estado, o sucateamento dos serviços públicos e a sistemática implementação de uma política macroeconômica lesiva à massa da população. O aprofundamento deste projeto, em condições que parecem tão adversas, depende da vontade majoritária da categoria profissional, mas também depende do revigoramento do movimento democrático e popular ${ }^{19}$.

Os primeiros resultados que surgem no Brasil do projeto societário inspirado no neoliberalismo (resultados que, aliás, reproduzem o que tem ocorrido em todo o mundo, privatização do estado desnacionalização da economia, desemprego, desproteção social, concentração de riqueza, etc.). O projeto ético-político tem futuro porque aponta precisamente para o combate (ético, teórico, político e prático social) ao neoliberalismo, para preservar e efetivar os valores que o informam ${ }^{19}$.

Vive-se hoje, na América Latina, de forma geral, neste início de século XXI, um regime do tipo democrático representativo com características formais. Isto significa que há eleições regulares, abertas e competitivas. Os líderes são escolhidos por meio destes mecanismos eleitorais, uma vez eleitos, governam por intermédio de instituições por tempo determinado. A sociedade tem o direito à organização, e a contestação política é permitida. Em outras palavras: a poliarquia está instituída ${ }^{14}$.

\subsection{O SERVIÇO SOCIAL E A DEMOCRACIA}

Uma sociedade é democrática quando, além de eleições, partidos políticos, divisão dos três poderes da república, respeito à vontade da maioria e das minorias, institui algo mais profundo, que é condição do próprio regime político, ou seja, quando institui direitos e que essa instituição é uma criação social, de tal maneira que a atividade democrática social realiza-se como uma contrapoder social que determina, dirige, controla e modifica a ação estatal e o poder dos governantes ${ }^{4}$.

A democracia proporciona oportunidades para: (1) participação efetiva; (2) Igualdade de voto; (3) Aquisição de entendimento esclarecido; (4) Exercer o controle definitivo do planejamento; (5) Inclusão dos adultos. Cada um desses critérios são necessários, pois se os membros (por mais limitado que seja seu numero) forem politicamente iguais para determinares as políticas da associação e quando essas exigências são violadas, os membros não serão politicamente iguais ${ }^{3}$.

O padrão clássico de Welfare State, que ganhou ampla aceitação após a Segunda Guerra Mundial e foi colocado em prática nos países do primeiro mundo, desenvolveu-se, essencialmente, num período de grande crescimento econômico. A política adotada nesses países promoveu uma melhoria das condições de vida de amplos setores da classe trabalhadora em todos os sentidos, apesar de permanecer a diferenciação de acordo com a qualificação e o tipo de trabalho realizado. Todavia, o Estado do BemEstar Social significou uma estratégia adotada pelo capitalismo para organizar uma nova forma de reprodução. Ele financiou o capital, e serviu de substrato ideológico para garantir a manutenção da sociedade capitalista, agora em um "novo" patamar: o "capitalismo humanizado",

O anseio pela existência de uma vida democrática, ou da vida social em um ambiente democrático, como uma reivindicação ou uma demanda humana - tanto individual quanto coletiva - onde a existência de um Estado Democrático de Direito aparece como o resultado das práticas dos cidadãos e do respeito aos 
direitos fundamentais. Trata-se, desta maneira, de entender a democracia não como simples regime político, ou como forma de governo, mas sim como forma social, como prática sociopolítica que se expressa no espaço cultural ${ }^{20}$.

As lutas sociais e as modificações do capitalismo e do próprio Estado possibilitaram a ampliação do espaço político, marcando o advento da sociedade liberaldemocrática com a conquista do sufrágio masculino, a liberdade de opinião, a liberdade de associação para os trabalhadores, o direito de greve etc. Foram transformações impulsionadas não apenas pelas lutas dos trabalhadores e pela influência dos pensamentos socialista e libertário, mas também pela transformação dos padrões de acumulação capitalista, que ampliaram os espaços do mercado interno, incorporando, como consumidores contribuintes, amplos contingentes sociais subalternos. É assim que a compreensão do sentido dos direitos humanos no quadro dos Estados de Bem-Estar Social requer uma análise do significado histórico e das transformações ocorridas no Estado Liberal e a própria consolidação das práticas democráticas ${ }^{20}$.

As lutas pelo Estado de Direito foram preponderantes, trazendo maior clareza sobre a democracia política do que a democracia social. Sem dúvida, as organizações contêm espaços de exercício e democracia direta participativa e de controle social. Os discursos da categoria (Assistente Social) são laudatórios a tais práticas e não há uma postura política coletiva que lhe seja defensiva em situações concretas ${ }^{21}$.

À discussão sobre a ampliação da dimensão política da democracia deve ser incorporado um outro elemento de igual importância: a condição sócio-econômica dos atores sociais que estão envolvidos no jogo democrático. Além da elevação do número de eleitores e das instâncias onde eles devem exercer o seu direito de voto, é preciso levar em conta o crescimento qualitativo do eleitorado, no que diz respeito ao seu nível de vida, de escolarização e às condições objetivas de participar das decisões políticas, dos processos administrativos e de exercer o controle sobre os seus representantes ${ }^{5}$.

O crescimento da exclusão social e da miséria, com as políticas de ajuste estrutural realizadas a partir dos anos 80 do século $\mathrm{XX}$, fez crescer o debate sobre a cidadania e os direitos humanos. Dessa forma, sob a interpelação da nova direita neoliberal, o debate contemporâneo obrigou a uma redefinição do campo progressista, se ampliando e mostrando em que medida existe um tensionamento em sociedades cada vez mais complexas, plurais, diversificadas e conflitivas. Por um lado, a exigência de relações democráticas - um alto grau de democracia - para dar conta desses múltiplos conflitos, complexidades e diversidades. Por outro lado, a colocação em xeque da própria institucionalidade democrática. E isso abre todo um campo de reflexão sobre os sujeitos sociais, a democracia e os direitos humanos como prática sociopolítica $^{20}$.

A política social no interior da cultura sóciopolítica e econômica brasileira terminam mais por constituir propostas fragmentadas de atenção à pobreza do que por garantir direitos sociais dentro de um sistema universal de proteção social. As análises da construção da democracia e dos direitos sociais como as cidadanias são essenciais para o posicionamento profissional do Assistente Social. É preciso que se trabalhe com uma concepção de direito social em contraposição àquela do direito positivo ${ }^{21}$.

A sociedade democrática institui direitos pela abertura do campo social à criação de direitos reais, à ampliação de direitos existentes e à criação de novos direitos. A democracia é a sociedade verdadeiramente histórica, isto é, aberta ao tempo, ao possível, às transformações e ao novo. Por isso mesmo, a democracia é aquela forma da vida social que cria para si própria um problema que não pode cessar de resolver, porque a cada solução que encontra, reabre o seu próprio problema, qual seja, a questão da participação ${ }^{4}$.

O movimento de construção democrática no Brasil foi atropelado pela lógica neoliberal a partir dos anos 90, agravando a questão social, notadamente nas áreas urbanas, quando ganham centralidade as políticas para as cidades. É, portanto, nas cidades, que a questão social concentra as mais dramáticas expressões, como o desemprego, a precarização das relações de trabalho, a insegurança social, a violência urbana. E também o aumento da repressão oficial sobre os pobres, a atualização de práticas higienistas, a retomada da ideia de classes perigosas, que é uma noção que remonta à transição do século passado no Brasil ${ }^{22}$. 
A questão social não é senão as expressões do processo de formação $e$ desenvolvimento da classe operária e de seu ingresso no cenário político da sociedade, exigindo seu reconhecimento como classe por parte do empresariado e do Estado. É a manifestação, no cotidiano da vida social, da contradição entre o proletariado e a burguesia, a qual passa a exigir outros tipos de intervenção mais além da caridade e repressão ${ }^{23}$.

O conceito de democracia inercial é usado para referir-se à democracia brasileira, onde há uma modernização das instituições políticas, uma evolução das leis, das regras, no sentido poliárquico. Contudo, pouco ou nada evolui na dimensão social, ou seja, é uma democracia inercial que apresenta as seguintes características: a) políticas econômicas que não favorecem as massas excluídas e que mantêm o desemprego inalterado e estagnado; b) uma cultura híbrida (misturada) que institucionaliza um comportamento de resignação e hostilidade com a política. Esta cultura política de resignação e hostilidade traduz-se em uma cultura de desconfiança generalizada em relação à política, assim como nas relações interpessoais na base da sociedade. O problema deste tipo de configuração cultural é que ele impede o funcionamento da democracia ${ }^{14}$.

\section{CONSIDERAÇÕES FINAIS}

Diante do exposto acima, refletimos a relação entre democracia e sociedade, através do projeto éticopolítico do Serviço Social, onde uma sociedade democrata representa a busca incessante pela igualdade e o acesso a todos os cidadãos aos direitos sociais.

Apesar de democracia remeter a ideia de liberdade em todos os sentidos, é necessária que seja exercida em sua plenitude com todos os indivíduos que compõem a sociedade com acesso a educação, trabalho e qualidade de vida de forma isonômica. A democracia exige uma atualização constante de seus líderes no sentido de atender as mudanças sociais.

A ênfase para o Código de Ética do Serviço Social ser democrático traz uma concepção inovadora para atenuar uma série de deficiências em relação as mudanças históricas que se inserem no neoliberalismo, influenciando a formação dos novos Assistentes Sociais para compreender as demandas sociais e buscar formas de minimiza-las, algo que só será alcançado quando os profissionais estiverem comprometidos com a efetivação prática do Código de Ética do Serviço Social.

Este artigo é imprescindível para nossa formação profissional, pois nos fez refletir a importância de conhecer a fundo o Código de Ética da profissão e sua relação com a sociedade democrática, através do conhecimento das problemáticas sociais e a ação do Assistente Social para compreender suas causas e os meios de atenua-las.

\section{REFERÊNCIAS}

1. SILVA, S.S.; KERN, F.A. O Processo de Materialização do Projeto ético-político do Serviço Social no Trabalho do Assistente Social. In: IV Mostra de Pesquisa da Pós-Graduação - PUCRS, $2009 . \quad$ Disponível em: <http://www.pucrs.br/edipucrs/IVmostra/IV_MOS TRA_PDF/Servico_Social/72092SOLANGE_DOS_SANTOS_SILVA.pdf> Acesso em 30 de abril de 2014.

2. NETTO, J.P (1990). "Notas sobre democracia e transição socialista". In: Democracia e Transição Socialista - Escritos de Teoria e Política. Belo Horizonte: Oficina de Livros.

3. DAHL, R.A. Sobre a Democracia. Brasília: UNB, 2001.

4. CHAUI, M. Cultura e democracia. In: Crítica y emancipación: Revista latinoamericana de Ciencias Sociales. Ano 1 (1). Buenos Aires: CLACSO, 2008.

5. NETO, A.C. Democracia: velhas e novas controvérsias. Estudos de Psicologia, 2(2): 287312. 1997.

6. MARKOFF, J. Democracia: transformações passadas, desafios presentes e perspectivas futuras. Sociologias, Porto Alegre, ano 15, (32): 18-50. 2013.

7. CARDIA, M. S. Cinco tipos de democracia institucional. Revista da Faculdade de Ciências Sociais e Humanas, n. 12, Lisboa, Edições Colibri, p. 309-316, 1998.

8. COUTINHO, C.N. 1980. A democracia como valor universal: notas sobre a questão democrática no Brasil. São Paulo: Livraria Editora Ciências Humanas. Disponível em: file:///C:/Users/Desktop/Downloads/A-democraciacomo-valor-universal.pdf Acesso em: 19 de abril de 2014 . 
9. VOUGA, C. A democracia ao sul da América uma visão tocquevilleana. Tempo Social; Rev. Sociol. USP, S. Paulo, 13(1): 117-128. 2001.

10. BOBBIO, N. 1909. Liberalismo e Democracia. Tradução de Marco Aurélio Nogueira. São Paulo: Editora Brasiliense, 2000.

11. BRASIL. Código de Ética do Assistente Social. Lei $n^{\circ} 8.662 / 93$ de regulamentação da profissão, de 13 de março de 1993. Brasília: CFESS, 2012.

12. BRASIL. Constituição (1988). Constituição da República Federativa do Brasil. Brasília, DF: Senado Federal: Centro Gráfico, 2006. 448 p.

13. REIS, C.A. Vontade Geral e Decisão Coletiva em Rousseau. Trans/Form/Ação, Marília, 33(2): 1134. 2010.

14. SANTOS, E, BAQUERO, M. Democracia e Capital Social na América Latina: Uma Análise Comparativa. Rev. Sociol. Polít., Curitiba, 28: 221234. 2007.

15. GANEM, A. O mercado como ordem social em Adam Smith, Walras e Hayek. Economia e Sociedade. 21(44): 143-164. 2012.

16. WESTPHAL, V.H. Democracia e participação: sentidos e usos no Serviço Social. In: XX Seminário Latinoamericano de Escuela de Trabajo Social. Córdoba, Argentina, 24 a 27 de setembro de 2012.

17. SARTI, I. A. Lei de Ferro de Michels e o Pluralismo: A Democracia na Guerra Fria. Rev. Sociol. Polít., Curitiba, 20(44): 73-81. 2012.
18. TONET, I. Marxismo e democracia. In: BORGES, LILIAM FARIA PORTO; MAZZUCO, NEIVA GALLINA. (orgs). Democracia e políticas sociais na América Latina. São Paulo: Xamã, 2009. DISPONIVEL

EM: http://www.ivotonet.xpg.com.br/arquivos/MARXIS MO_E_DEMOCRACIA.pdf> Acesso em: 16 de abril de 2014.

19. NETTO, J.P. A construção do projeto ético-político do Serviço Social frente a crise contemporânea. In: Capacitação em Serviço Social e Política Social: módulo 1: crise contemporânea, questão social e serviço social. Brasília: CEAD, 1999.

20. FREITAS, F.F.B. 2008. Viver a Democracia: uma breve análise sobre Democracia, Direitos Humanos e Cidadania. Disponível em: http://www.dhnet.org.br/dados/cursos/edh/redh/02/ modulo_2_1_fabio_viver_a_democracia.pdf Acesso em: 18 de abril de 2014.

21. GREGORIO, F.J. O Serviço Social e a Democracia. In: $2^{\circ}$ SEMINÁRIO NACIONAL ESTADO E POLITICAS SOCIAIS NO BRASIL, 2005, Cascavel-PR: UNIOESTE.

22. RAICHELIS, R. O. Controle Social Democrático na Gestão e Orçamento Público 20 Anos Depois. In: Seminário Nacional - O Controle Social e a Consolidação do Estado Democrático de Direito Conselho Federal de Serviço Social - CFESS (organizador). Brasília, 2011.

23. IAMAMOTO, M.; CARVALHO R. Relações Sociais e Serviço social no Brasil. $35^{\circ}$ Edição. São Paulo: $\quad$ Editora 2011. 